\title{
Seronegative Bilateral Symmetrical Inflammatory Polyarthritis: Think Twice Before Starting Immunosuppression
}

\author{
Omar Alsaed, Nawal Hadwan, Izzat Khanjar, Abdul-Wahab Al-Allaf \\ ${ }^{1}$ Department of Medicine (Rheumatology), Hamad Medical Corporation, Doha, Qatar
}

Doi: 10.12890/2018_000895 - European Journal of Case Reports in Internal Medicine - ๑ EFIM 2018

Received: 04/04/2018

Accepted: $13 / 04 / 2018$

Published: 04/06/2018

How to cite this article: Alsaed O, Hadwan N, Khanjar I, Al-Allaf AW. Seronegative bilateral symmetrical inflammatory polyarthritis: think twice before starting immunosuppression. EJCRIM 2018;5: doi:10.12890/2018_000895.

Conflicts of Interests: The Authors declare that there are no competing interests.

This article is licensed under a Commons Attribution Non-Commercial 4.0 License

\section{ABSTRACT}

The most common cause of bilateral symmetrical polyarthritis in the small joints is rheumatoid arthritis. However, if seronegative arthritis is involved, it could be the case that other underlying causes need to be diagnosed. This is particularly important for those coming from or living in developing countries where infectious causes should always be considered. The case of a young Nepali woman is presented in this article. She was referred as a case of seronegative rheumatoid arthritis for DMARDs therapy but this was not the case due to her origin from Nepal and seronegativity for RF, Anti-ccp, and ANA as well as faint macular skin lesions over her face and upper extremities, which the patients are not aware of. Consequently, skin biopsy was carried out which subsequently confirmed that the infectious cause of her polyarthritis was leprosy.

\section{LEARNING POINTS}

- Bilateral symmetrical seronegative inflammatory arthritis of rheumatoid type is very common.

- However, when both RF and anti-ccp are negative, other possible secondary causes including infection should be considered, especially in patients from areas where disease is endemic.

- In this case lepromatous leprosy was the cause of the patient's presumed rheumatoid arthritis and all her arthritis resolved after her leprosy had been treated.

\section{KEYWORDS}

Seronegative rheumatoid arthritis, leprosy

\section{INTRODUCTION}

Leprosy (also known as Hansen's disease) is an infectious disease caused by Mycobacterium leprae that involves the skin and peripheral nerves. Leprosy is a significant global health concern in certain areas. Early diagnosis and a full course of treatment are critical for preventing lifelong neuropathy and disability.

The prevalence of leprosy varies. The overwhelming majority of cases are found in developing countries. Of the 16 countries reporting more than 1000 new cases annually in 2009, the largest numbers of new cases were seen in India, Brazil, Indonesia, Bangladesh, and Nigeria. However, since international travel is increasing, patients with leprosy may present anywhere ${ }^{[1]}$.

The disease probably spreads via the respiratory route. Nasal discharge from untreated patients with lepromatous (multibacillary) disease frequently contains large numbers of bacilli[ ${ }^{2]}$. 
We report this case to raise awareness among general practitioners and rheumatologists of infectious causes, including leprosy, when dealing with patients from developing countries presenting with presumed seronegative rheumatoid arthritis as the two different conditions require totally different treatment.

\section{CASE PRESENTATION}

A 32-year-old Nepali lady with no significant past medical history presented with pain and swelling in multiple joints involving hands, wrists, feet, and knees with early morning stiffness of more than one hour for two weeks duration. She reported no constitutional symptoms, recent flu or diarrheal illness. Her roommate had noted some faint red skin rash over her face for the preceding 6 months which the patient herself was not aware of. The skin rash was not itchy. The patient worked in Qatar as a cleaner in a kindergarten. She came from Nepal nine months prior to her presentation. She was not aware of having had any contact with any sick child. She is married and her family is in Nepal. She does not have any extra-marital sexual relationships.

\section{Examination}

She was a healthy looking woman with a BMI of 32. She had erythematous macular lesions involving the face, anterior aspect of the neck, back of the chest, and both arms. The rash was non-blanching, non-scaly, and sensations were intact over the skin lesions (Fig. 1). There was no lymphadenopathy. Examination of her hands revealed puffiness over the dorsum of the hands with hyper-pigmented skin. The patient was unable to perform a complete fist. She had tender and swollen wrists, MCPs, PIPs, MTPs, ankles, and knees (Fig. 2) with moderate restriction of range of motion in the affected joints.

Investigations revealed: WBC 7.6 (neutrophil 72\%), with low hemoglobin of $8.5 \mathrm{mg} / \mathrm{dl}$, MCV 76.6, platelets 270 . Inflammatory markers raised with ESR $66 \mathrm{~mm} / \mathrm{hr}$ and CRP $208 \mathrm{mg} / \mathrm{L}$. U\&Es, LFTs, urine dipstick, and hands X-ray were all normal. Parvovirus B19 IgG positive, but the IgM was negative. ACPA, RF, and ANA were all negative.

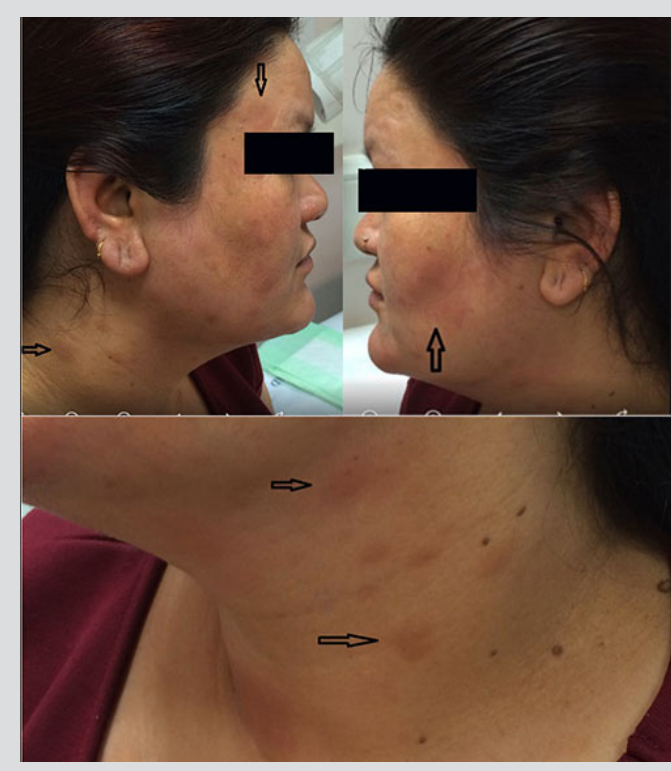

Figure 1. The non-blanching, non-scaly rash faint erythematous
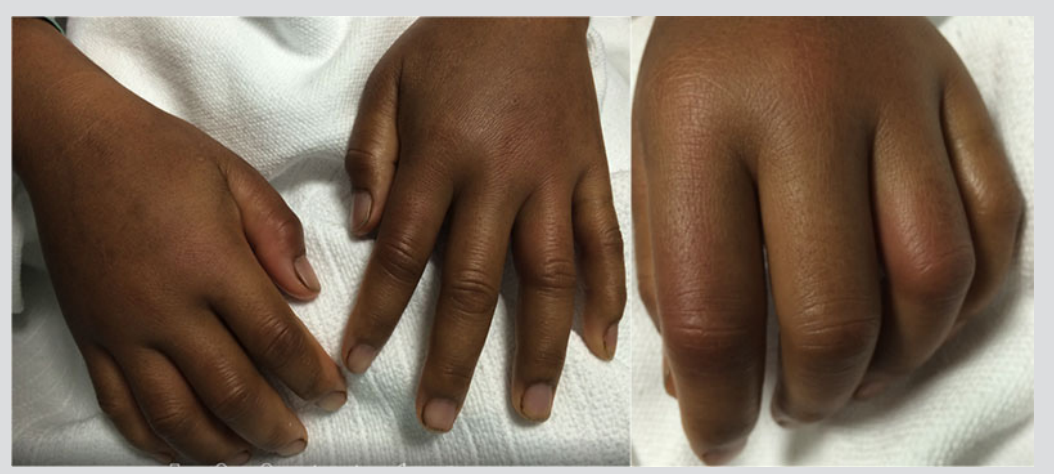

Figure 2. The swollen wrists, MCPs, PIPs, MTPs, with moderate restriction of range of motion in the affected joints

\section{Progress}

The patient was initially treated with naproxen $500 \mathrm{mg}$ BID as a case of possible viral-associated arthritis. In spite of this, she continued to be significantly symptomatic with joint pain and stiffness. Another possible differential diagnosis entertained was a possible early rheumathoid arthritis (RA). We refrained from starting DMARDs because of the short duration of her arthritis. Biopsy of the skin lesion was carried out which found leprosy with borderline subtype (Fig. 3). 


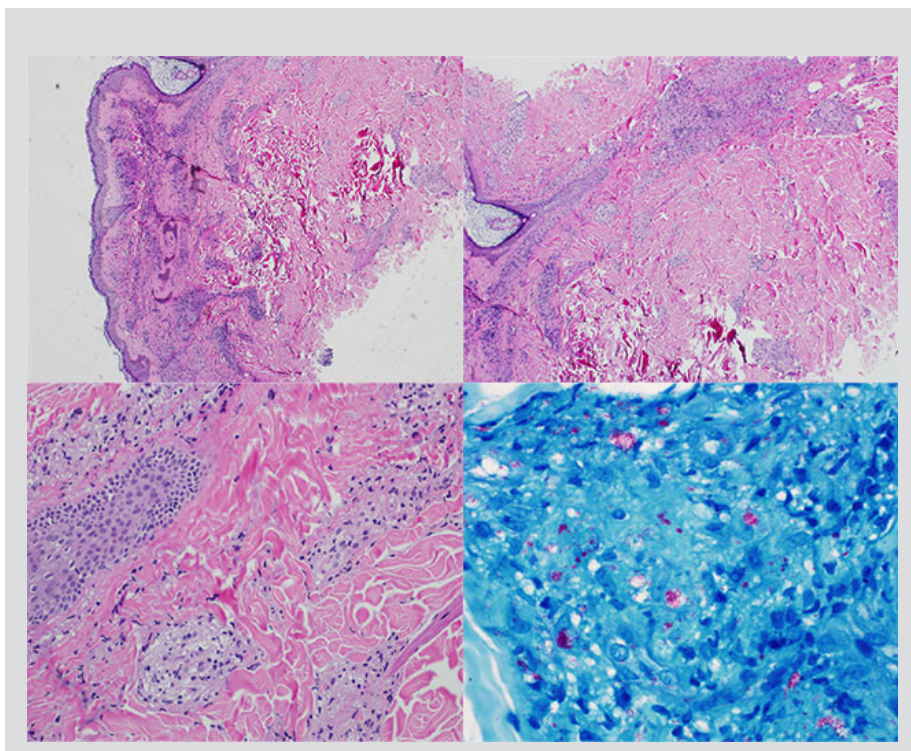

Figure 3. Skin shows several foci of superficial and deep epithelioid granulomata with focal extension into the subcutaneous fat. Some of the granulomas are engulfing nerves. No interface changes are seen.

There is no evidence of dysplasia or malignancy

The special stains (Wade-Fite, ZN, and sliver) show a large number of Bacilli with a more diffuse histiocytic infiltrate consistent with leprosy. The more diffuse pattern and a large number of bacilli favor borderline leprosy subtype rather than tuberculoid subtype. Immunofluorescence studies using antibodies against $\lg G, \lg A, \lg M, C 3, C 19$, and fibrinogen are negative.

\section{DISCUSSION}

Leprosy is an infectious disease caused by Mycobacterium leprae and the classical manifestation of leprosy is neuro-cutaneous signs and symptoms. However, musculoskeletal manifestations are rarely reported. There are publications for arthritis in leprosy but we think it is still under-recognized for general health care practitioners especially when dealing with what looks like seronegative rheumatoid arthritis. This is very important especially when the patient is from a developing country.

Infectious causes should always be considered in these patients and the type of infection will depend on the geographical origin of the patient and what endemic diseases are prevalent in that place of origin.

Epidemiological data concerning the prevalence of arthritis in leprosy varies depending on geographical area and on the Reporting Centre. Various studies have reported it to range from 1 to $78 \%{ }^{[3-5]}$. In one of the largest studies from India, only 27 out of 2500 patients with leprosy had articular involvement amounting to just over $1 \%{ }^{[6]}$. However, studies from other parts of the world have revealed a much higher rate of arthritis in leprosy. Cossermelli-Messina et al[ ${ }^{[7]}$ from South America reported arthritis in 12 out of 44 patients with leprosy (27\%), Gibson et $a^{\left[{ }^{[8]}\right.}$ from Pakistan reported arthritis in 12 out of 31 patients (39\%), and Alcocer et al ${ }^{[9]}$ observed a very high prevalence rate in his series of leprosy patients (78\%).

Arthritis in leprosy can be classified into two groups: charcot joints arthritis and acute polyarthritis of lepra reaction. Charcot joint arthritis is the most common form of arthritis in leprosy, which is due to leprous neuropathy. It usually involves the weight-bearing joints of the lower limbs, i.e. the ankles and knees and causes debilitating deformities. The acute polyarthritis type is usually part of immunologic lepra reactions. It is an acute symmetrical inflammatory polyarthritis affecting the small joints of the hands and feet, resembling rheumatoid arthritis. In 1964 Lele et al ${ }^{[10]}$ documented 13 cases of leprosy that had developed acute painful symmetrical polyarthritis involving the small joints of the hands. Then in 1969 Modi and Lele $e^{[11]}$ presented data for 21 cases with lepra reaction associated with arthritis.

Immunologic lepra reactions are systemic inflammatory complications that occur either before treatment (some patients initially present for medical attention in the setting of a reaction), during treatment, or months to years after treatment. These reactions may affect $30-50 \%$ of all leprosy patients ${ }^{[12]}$.

In reviewing the literature it was found that many cases of polyarthritis related to lepra immunologic reaction were thought to be seronegative rheumatoid arthritis or peripheral spondyloarthritis and treated using DMARDs, and in some cases even biology therapy.

The patient in the case presented in this article was initially treated as a case of virally associated polyarthritis. It was thought to be a case of early rheumatoid arthritis but due to the persistence of the unusual skin rash and with the patient being from Nepal, no steroid or DMARDs were used before any possible infection had been excluded. The skin biopsy was part of our workup and clearly revealed the correct diagnosis. It was subsequently discovered that Nepal is a highly endemic area for leprosy. Following this, more cases of leprosy have been discovered and these were diagnosed correctly from the first visit, which we hope to report on in the future as a case series.

Accordingly, our case was referred to the infectious disease Centre for treatment. She was put on the correct regimen for treating leprosy 
which includes dopson $100 \mathrm{mg}$ daily, rifampicin $300 \mathrm{mg}$ monthly, clofazimine $100 \mathrm{mg}$ monthly, and tapering dose of prednisolone. After 3 months she had complete resolution of her polyarthritis and a significant reduction in the size and number of the skin lesions. The skin lesions need a much longer time (up to 2 years) before they disappear and are completely resolved. The treatment will continue for 2 years which is the usual treatment for leprosy.

\section{CONCLUSION}

Infectious causes always need to be considered in patients from developing countries with what in particular looks like seronegative rheumatoid arthritis as treatment is totally different. The type of infection depends on what is endemic in the geographical area of origin of the patient so physicians including rheumatologists should be highly suspicious when diagnosing rheumatoid arthritis. Consequently, anything unusual such as the skin rash in the case presented in this article should be checked for.

\section{REFERENCES}

1. Global leprosy situation, 2010. Wkly Epidemiol Rec 2010;85:337

2. Abraham S, Mozhi NM, Joseph GA, et al. Epidemiological significance of first skin lesion in leprosy. Int J Lepr Other Mycobact Dis 1998;66:131.

3. Bonvoisin B, Martin JM, Bouvier M, Bocquet B, Boulliat J, Duivon JP. Articular manifestations of leprosy. Sem Hop 1983;59:302-5.

4. Atkin SL, el-Ghobarey A, Kamel M, Owen JP, Dick WC. Clinical and laboratory studies of arthritis in leprosy. Br Med J 1989;298:1423-5.

5. Albert DA, Weisman MH, Kaplan R. The rheumatic manifestations of leprosy [Hansen disease]. Medicine 1980;59:442-8.

6. Lele RD, Sainani GS, Sharma KD et al. Leprosy presenting as rheumatoid arthritis. J Assoc Physicians India 1965;13:275-7.

7. Cossermelli-Messina W, Festa Neto C, Cossermelli W. Articular inflammatory manifestations in patients with different forms of leprosy. J Rheumatol 1998;25:111-9.

8. Gibson T, Ahsan Q, Hussein K. Arthritis of leprosy. Br J Rheumatol 1994;33:963-6.

9. Alcocer J, Herrera R, Lavelle C, Guidino J, Fraga A. Inflammatory arthropathy in leprosy. Arthritis Rheum 1979;22:587.

10. Lele RD, Sainani GS, Sharma KD et al. Leprosy presenting as rheumatoid arthritis. J Assoc Physicians India 1965;13:275-7.

11. Modi TH, Lele RD. Acute joint manifestations of leprosy. J Assoc Physicians India 1969;17:247-54.

12. Scollard DM. Time and change: new dimensions in the immunopathologic spectrum of leprosy. Ann Soc Belg Med Trop 1993;73 Suppl 1:5.

13. Rath D, Bhargava S, Kundu BK. Leprosy mimicking common rheumatologic entities: a trial for the clinician in the era of biologics. Case Rep Rheumatol $2014 ; 429698$. 